\title{
Improvement of adaptive fuzzy control to adjust speed for a doubly fed induction motor drive (DFIM)
}

\author{
Dahhou Brahim ${ }^{1}$, Bendjebbar Mokhtar ${ }^{2}$, Lachtar Salah $^{3}$ \\ 1,2 Departement of Electrical Engineering, Oran University of Science and Technology-Mohamed Boudiaf, \\ Algeria \\ ${ }^{3}$ Centre de Développement des Energies Renouvelables, Algeria
}

\begin{tabular}{l} 
Article Info \\
\hline Article history: \\
Received Jun 3, 20 \\
Revised Jul 26, 20 \\
Accepted Aug 9, 201 \\
\hline Keywords: \\
AFLPI controller \\
DFIM \\
FLPI controller \\
PI controller \\
Speed tracking \\
Torque tracking
\end{tabular}

\section{Corresponding Author:}

Dahhou Brahim, Departement of Electrical Engineering, Oran University of Science and Technology - Mohamed Boudiaf, El Mnaouar, BP 1505, Bir El Djir 31000, Oran, Algeria.

Email: alidahhou@gmail.com

\begin{abstract}
This paper presents the doubly fed induction motor (DFIM) speed control using adaptive fuzzy logic PI (AFLPI) controller to give better dynamic performances. Before the advent of modern technology, integral proportional based current controller is usually used due to its simplicity. But, the effectiveness of closed-loop control is widely affected by applied this type of controls, taking into account that the PI controllers have tuning problems. To overcome the problem, a new technique AFLPI based speed controller for direct field oriented control fed DFIM to get fast speed response and to minimize the torque ripple. The application of this type of control is very satisfactory to replace the conventional PI controller and, even the fuzzy logic PI (FLPI) controller. The performances of DFIM driving under the field-oriented application are simulated under different operating conditions using the AFLPI controller. The simulation results obtained with AFLPI are compared with those obtained in the case of the FLPI controller and the conventional PI controller. Accordingly, an improvement in dynamic and robustness is clearly appears in AFLPI controller simulation results compared to the others aforementioned controllers. Simulation Results are presented for the three techniques using Matlab/Simulink to prove the dynamic performances and robustness.
\end{abstract}

This is an open access article under the CC BY-SA license.

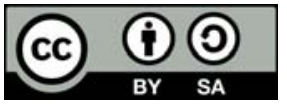

\section{INTRODUCTION}

Doubly fed induction motor (DFIM) has a key role in the industrial field because of its low cost, rigidity, reasonable dimension, low maintenance and it's one of the most largely electric motors used to convert electrical energy to mechanical energy. In addition, The DFIMs have been shown promising prospects as a machine in the variable speed applications [1-3]. The control techniques applied to electric motors become effective thanks to advances in semiconductor components and digital technologies $[4,5]$.

The DFIM control flexibility is very higher due to independent of flux, torque, slip and power factor [6]. The DFIM structure makes it possible to measure the quantities of rotor currents, which makes the acquisition of the flux vector necessary for vector control purposes depend only on the knowledge of the motor reactance.

The DFIM structure makes it possible to adjust the input and output rotor windings flux in order to obtain both a variable speed in super-synchronous or sub-synchronous modes characterized. However, the 
major obstacle that makes the DFIM control complicated, is the difficulty to obtain the decoupling of the torque and the flux. To overcome this obstacle, an algorithm with high performances was developed to allow easily to the DFIM control [7, 8].

Conventional PI controllers can only be tuned at a specific operating point, and the change of this operating point maks these types of controllers act in an unsatisfactory manner. To solve this problem, fuzzy logic controllers can be replaced the conventional PI controllers. However, this type of controller has a major drawback, when specialized knowledge is required to determine the membership functions and the rules. To eliminate the aforementioned drawback, it must be using the combination of both controllers namely adaptive fuzzy logic controller [9].

The performance satisfaction for an electromechanical closed-loop control application is generally required controlling the speed by a PI controller to eliminate the static error and reduce the speed response time. Many techniques have been applied to adjust the PI controller in order to eliminate the speed overshoot when starting the motor which is related to the controller and the machine parameters $[10,11]$.

The combination of PI controllers and AFL technology is expressed among recent research topics in the control of electrical machines [12-14]. Recently, the combined AFLPI controller has largely used in industrial applications to improve the results of nonlinear and complex processes. Among the AFLPI controller performances is robustness, do not need a precise mathematical electric machine model and the insensitivity to parameter variations. In recent decades, modern technology allowed the fast increasing development of approximation theory, as an adaptive control method was introduced to deal with nonlinear parametric uncertainty systems based on a fuzzy logic system $[15,16]$. The main two drawbacks of the FLPI controller design are respectively, getting an adequate rule for the application and selecting scaling factors prior to fuzzification and defuzzification, as expediting the design determination parameters and reduce the computation time are the appropriate solution to overcome these drawbacks.

Several adaptive techniques have been proposed as solutions to overcome these problems. In [17], the authors present an online method for adapting the scaling factors of the FL controller, this method is considered as a solution to design an adaptive fuzzy controller. The aim of the proposed technique is to adapt online scaling factors according to a performance measure, and the purpose of that is to refine the controller and improve the drive system performance.

In this paper, AFLPI controller performances investigation to improve DFIM FLPI speed controller gains. The paper is organized as follows. In section 2, the DFIM model, field-oriented control and inverter are developed. The methodology approaches of the AFLPI controller and FLPI controller are presented, in section 3. The simulation results and their discussion are presented in section 4 . Finally, the conclusion is presented in the last section.

\section{DESCRIPTION OF THE SYSTEM}

The closed-loop system is illustrated in Figure 1 below, two converters (rectifier and inverter) are presented respectively, the first is connected to the stator and the other is connected to the rotor [18].

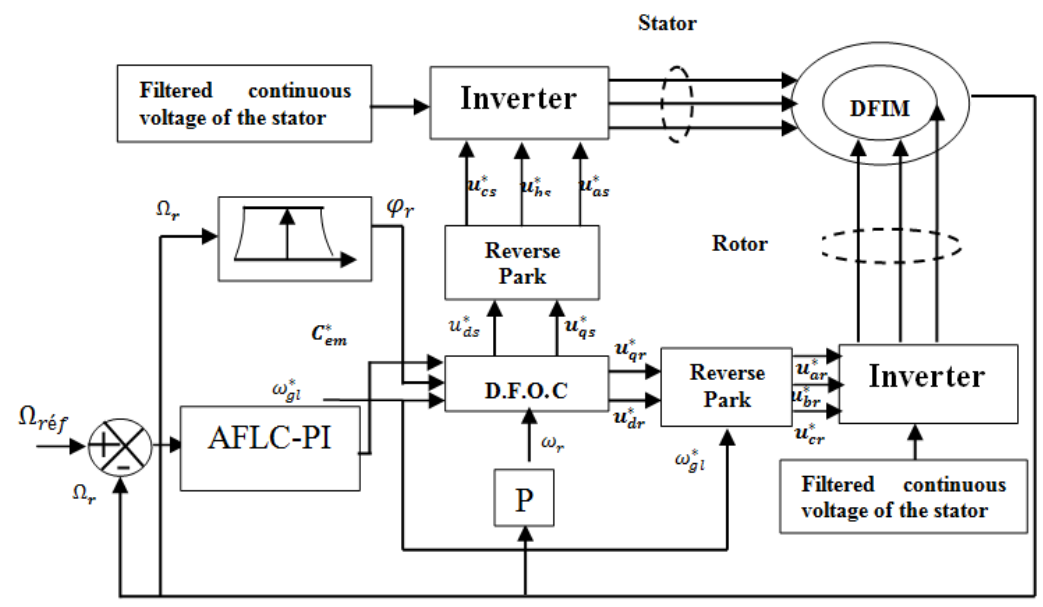

Figure 1. Global scheme of the studied system with adjustment speed control 
The DFIM mathematical model must be taken into account some simplify hypotheses to get a dynamic model make it possible to control the electrical system. [19].

\section{MODELING SYSTEM}

Simplifying assumptions are necessary to avoid the DFIM structure complexity and getting a dynamic model [20]: Considering that the rotor is symmetrical with a uniform air-gap, the magnetic circuit is perfectly laminated and not saturated, with sort of the iron losses and hysteresis are negligible and only the windings are through by currents; stator and rotor phases are created the MMFs considered perfectly sinusoidal distributions along the gap. Therefore, the DFIM mathematical dynamic model is described as follow:

$$
\left\{\begin{array}{c}
\dot{x}=A x+B u \\
y=C x
\end{array}\right.
$$

where,

$$
\begin{aligned}
& x=\left[\mathrm{i}_{\mathrm{sd}} \mathrm{i}_{\mathrm{s} q} \mathrm{i}_{r \mathrm{~d}} \mathrm{i}_{r q}\right]^{T}: \text { is the state vector } \\
& u=\left[V_{\mathrm{sd}} V_{\mathrm{sq}} V_{r \mathrm{~d}} V_{r q}\right]^{T}: \text { is input vector } \\
& A=\left[\begin{array}{cccc}
\frac{-R_{S}}{\sigma L_{s}} & \frac{(1-\sigma) \omega+\omega_{S}}{\sigma} & \frac{R_{r} M}{\sigma L_{S} L_{r}} & \frac{M \omega}{\sigma L_{S}} \\
\frac{(1-\sigma) \omega+\omega_{S}}{\sigma} & \frac{-R_{S}}{\sigma L_{s}} & \frac{M \omega}{\sigma L_{s} L_{r}} & \frac{R_{r} M}{\sigma L_{S} L_{r}} \\
\frac{R_{S} M}{\sigma L_{s} L_{r}} & \frac{-M \omega}{\sigma L_{r}} & \frac{-R_{S}}{\sigma L_{s}} & \frac{\sigma \omega_{S}-\omega}{\sigma} \\
\frac{M \omega}{\sigma L_{r}} & \frac{R_{S} M}{\sigma L_{S} L_{r}} & \frac{\omega-\sigma \omega_{S}}{\sigma} & \frac{-R_{S}}{\sigma L_{S}}
\end{array}\right]
\end{aligned}
$$

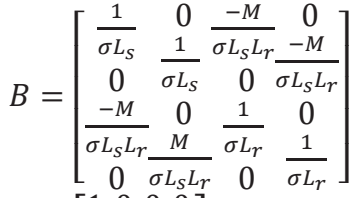

$$
\begin{aligned}
& C=\left[\begin{array}{llll}
1 & 0 & 0 & 0 \\
0 & 1 & 0 & 0 \\
0 & 0 & 1 & 0 \\
0 & 0 & 0 & 1
\end{array}\right]
\end{aligned}
$$

The overall DFIM dynamic model in the $d-q$ plan can be reported as following [21]:

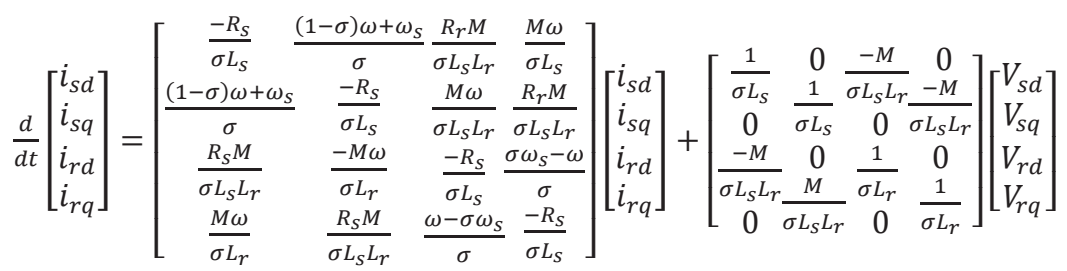

The mechanical equation is given as follow:

$$
\mathrm{J} \frac{d \Omega}{d t}=T_{e m}-T_{l}-k_{f} \Omega
$$

The electromagnetic torque expression is given as follow :

$$
T_{e m}=P \frac{M}{L_{r}}\left(\varphi_{r d} i_{s q}-\varphi_{r q} i_{s d}\right)
$$

Where

$\theta_{s}, \theta_{r} \quad:$ Stator and rotor electrical angles

$\theta ; \Omega \quad$ : Rotor mechanical position and speed 


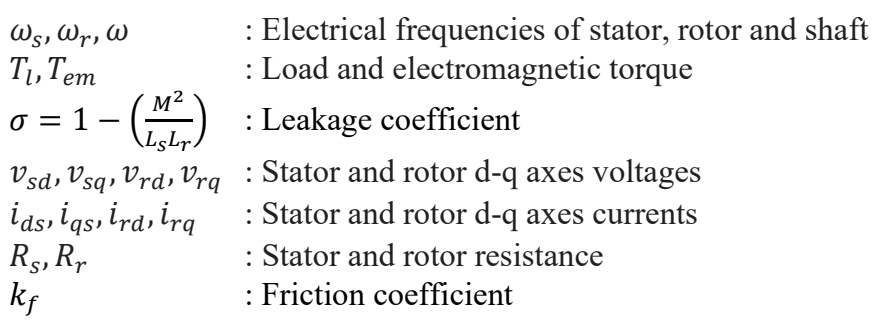

The purpose of vector control is to ensure decoupled control of flow and torque [22]. In the Figure 2 clearly shows the vector representation of vector control in the synchronous frame of reference whose axis $\mathrm{d}$ is aligned with the rotor flux vector $\varphi_{r d}=\varphi^{*}$ and $\varphi_{q r}=0$.

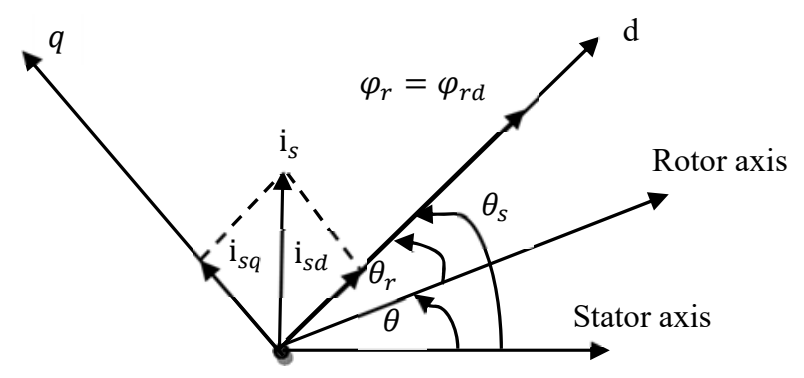

Figure 2. Rotor orientation diagram

In order to obtain a good decoupling between the axes $\mathrm{d}$ and $\mathrm{q}$, the intermediate voltages are defined by the following equations:

$$
\left\{\begin{array}{l}
\mathrm{V}_{\mathrm{tsd}}=\mathrm{V}_{\mathrm{sd}}-\frac{\mathrm{M}}{\mathrm{L}_{\mathrm{r}}} \cdot \mathrm{V}_{\mathrm{rd}} \\
\mathrm{V}_{\mathrm{tsq}}=\mathrm{V}_{\mathrm{sq}}-\frac{\mathrm{M}}{\mathrm{L}_{\mathrm{r}}} \cdot \mathrm{V}_{\mathrm{rq}} \\
\mathrm{V}_{\mathrm{trd}}=\mathrm{V}_{\mathrm{rd}}-\frac{\mathrm{M}}{\mathrm{L}_{\mathrm{s}}} \cdot \mathrm{V}_{\mathrm{sd}} \\
\mathrm{V}_{\mathrm{trq}}=\mathrm{V}_{\mathrm{rq}}-\frac{\mathrm{M}}{\mathrm{L}_{\mathrm{s}}} \cdot \mathrm{V}_{\mathrm{sq}}
\end{array}\right.
$$

The transfer functions connecting the stator and rotor components of each axis are:

$$
\left\{\begin{array}{l}
\frac{I_{s d}(s)}{V_{t s d c}(s)}=\frac{I_{s d}(s)}{V_{t s q c}(s)}=\frac{1}{R_{s}+\sigma L_{s} \cdot S} \\
\frac{I_{r d}(s)}{V_{\operatorname{trdc}(s)}}=\frac{I_{r q}(s)}{V_{\operatorname{trqc}(s)}}=\frac{1}{R_{r}+\sigma L_{r} \cdot S}
\end{array}\right.
$$

\section{ADAPTIVE FUZZY CONTROL DESIGN FOR DFIM}

Regarding the adaptive fuzzy controller which is based on the theory of the yapunov, we proceed according to two phases, at the beginning we start by designing a fuzzy PI controller, whereas later and secondly, we decide to the method of determining the gains of a fuzzy regulator based on the aforementioned theory. This controller that we applied to DFIM is under the assurance of a controller of the FLPI type[23,24]. In this work, we implemented another strategy, completely new which ensures adaptive fuzzy control based on the theory of the yapunov to delimit the gains $K_{e}$ and $K_{d c e}$ (normalized), being able to be implemented in a vast class of nonlinear systems it is argued that the advantages of two techniques are assembled and are both known to be very solid, in this case, the control by fuzzy logic and the adaptive one [25].It is however possible to highlight what characterizes the application of the controller on a DFIM so that it follows the reference speed. 


\section{STUDY OF THE ADAPTATION MECHANISM}

There are many notions of stability for dynamic systems. We will study the following notion:

- $\quad$ Asymptotic stability: Lyapunov stability and trajectories tend asymptotically to 0 .

We consider a nonlinear system whose mechanical equation of DFIM is described in the following form:

$$
\frac{\mathrm{J}}{s} \frac{d \Omega_{r}(t)}{d t}=T_{e m}-T_{l}-\frac{k_{f}}{s} \Omega_{r}(t)
$$

The previously equation can reformulated as follow:

$$
\dot{\Omega}_{r}(t)=\frac{d \Omega_{r}(t)}{d t}=b_{p} T_{e m}(t)-d_{p} T_{l}-a_{p} \Omega_{r}(t)
$$

By replacing equation (43) in equation (44), we obtain the following form:

$$
\dot{\Omega_{r}}(t)=-a_{p} \Omega_{r}(t)+b_{p} T_{e m}^{*}(t-1)+b_{p} K_{d c e} d T_{n e m}(t)-d_{p} T_{l}
$$

The error e ( $\mathrm{t}$ ) and its derivative $\frac{d e(t)}{d t}$ are used to build the base of the adaptation mechanism of the adaptive fuzzy logic controller. Each size of the adaptation mechanism is of the following form: The speed error noted e (t) is defined by:

$$
e(t)=k_{e}\left(\Omega_{\text {réf }}-\Omega_{r}(t)\right)(13)
$$

The derivative of the speed error noted by:

$$
\dot{e}(t)=\frac{d e(t)}{d t}=k_{e}\left(\frac{d \Omega_{\text {réf }(t)}}{d t}-\frac{d \Omega_{r}(t)}{d t}\right)
$$

So, we get as follows:

$$
\dot{e}(t)=\frac{d e(t)}{d t}=k_{e}\left(-a_{p} \Omega_{r}(t)+b_{p} T_{e m}^{*}(t-1)+b_{p} K_{d c e} d T_{n e m}(t)-d_{p} T_{l}\right)
$$

Since $\frac{d \Omega_{r e ́ f(t)}}{d t}=0$ analysis of the stability of the proposed order.

\section{RESULTS AND DISCUSSION}

After the contribution and implementation of the machine model with different types of speedadjustable control in the Matlab/Simulink environment, the torque and speed simulation result is shown in the Figure 3.The machine operating in its nominal condition with a reference speed $150 \mathrm{rad} / \mathrm{s}$, a torque load $T_{l}=$ 10 N.m applied at $(0.7 \mathrm{~s}<\mathrm{t}<1.7 \mathrm{~s})$.

In this section, the performances of the proposed control scheme are illustrated by numerical simulation. Meanwhile, the proposed control method compared with FLPI controller in terms of response to speed variation, sensitivity to external load disturbances and robustness against parameter variations.

Note that all the design parameters in those control systems are chosen to achieve a satisfactory transient control performance considering the requirement of stability.

Comparative performances of AFLPI controller, FLPI controller and PI controller for tests performed under the same conditions are studied. The response of DFIM is observed under different operating conditions such as a step change in the control speed or a sudden change in the load.

Results of a set of tests of step changes in speed reference are shown in Figure 3 (c), Figure 4 (c), Figure 5 (c) and Figure 6 (c) for the DFIM. Variation in the reference speed at: $t>0.25$ sec and $t<$ $1 \mathrm{sec}, \Omega=150 \mathrm{rad} / \mathrm{s}, t>1 \mathrm{sec}$ and $t<2 \mathrm{sec}, \Omega=-150 \mathrm{rad} / \mathrm{s}$ and $t>2 \mathrm{sec}, \Omega=0 \mathrm{rad} / \mathrm{s}$, and a torque load $T_{l}=10$ N.m applied at $(0.7 \mathrm{~s}<\mathrm{t}<1.7 \mathrm{~s})$.

In these tests the performance of the three controllers is evaluated in terms of speed response. It can be seen that the amplitude of transient oscillations of speed is lower with AFLPI controller which also has better rejection of perturbations. The results demonstrate that the AFLPI controller shows improvement, albeit small, in performance compared with the FLPI controller and conventional PI controller.

Int J Pow Elec \& Dri Syst Vol. 11, No. 1, Mar 2020 : 496-504 
The estimated speeds deviate from the speed references when the conditions of the each DFIM are different. Steady-state errors in speed and electromagnetic torque variations are interrelated due to the motors being connected in parallel and there being coupling terms between the d-q axes of each motor.

Finally, the simulation results of the DFIM using AFLPI controller, FLPI controller and PI controller were also analyzed regarding load torques and speed variations. These results confirm that the AFLPI controller demonstrates a slightly better performance under changing operating conditions and presents satisfactory performance.

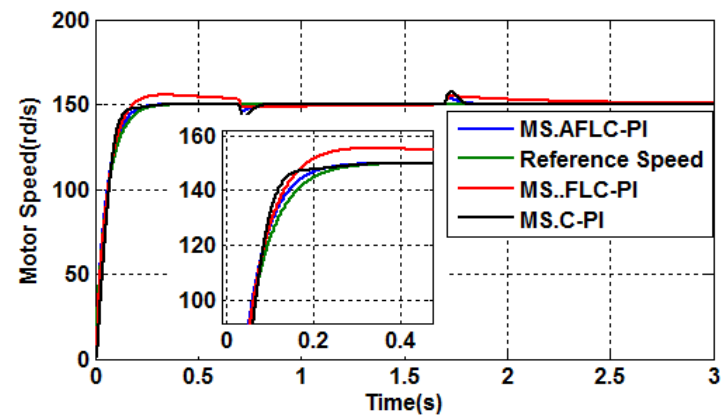

(a)

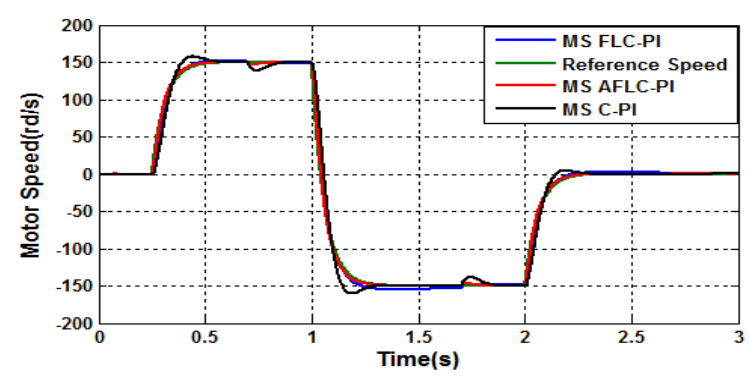

(c)

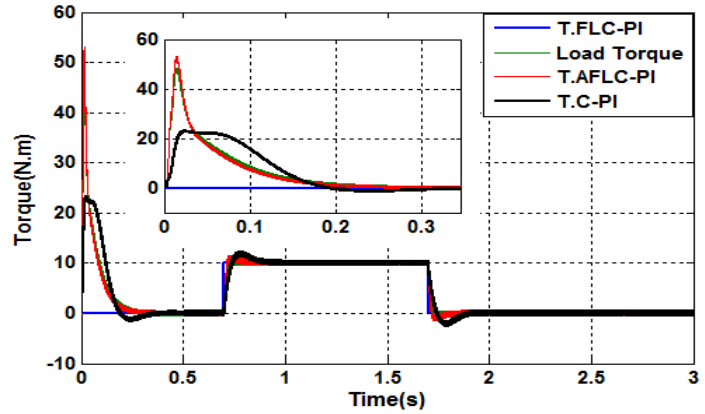

(b)

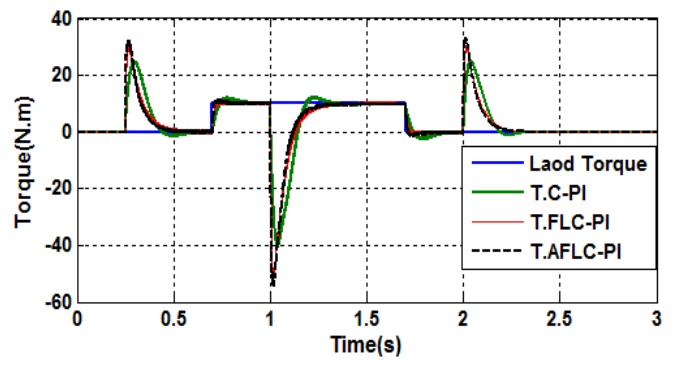

(d)

Figure 3. Rotation speed and electromagnetic torque evolution under nominal parameters conditions. (a) Rotation speed for a steady-state reference speed conditions. (b) Electromagnetic torque corresponding to the rotor speed conditions. (c) Rotation speed for an alternate reference speed conditions. (d) Electromagnetic torque corresponding to the rotor speed conditions.

Test with DFIM with perturbation parameters

Test 1: the motor is operating at the same conditions aforementioned (nominal conditions). To study the effect of parameters variation on the performance of the different controllers, an increase with $\mathrm{Rr}=1.5 \mathrm{Rr}$, the performance of DFIM drive is greatly affected by the variation of this parameter especially at low speed at $\mathrm{t}=$ $0.7 \mathrm{sec}$ and $t=1.7 \mathrm{sec}$. But the conventional PI and FLPI controllers responses are larger than the margin value of AFLPI controller are shown on speed response in Figure 4 (a), on torque response in Figure 4 (b), also on the speed and torque responses when applying an alternate speed reference respectively in Figure 4 (c) and Figure 4 (d).

Test 2: an increasing of the stator resistance Rs=1.5Rs. From Figure 5, we can see that at starting up with no load or in case of nominal load, the AFLPI controller reaches its speed reference rapidly with a little overshoot compared to the FLPI or conventional PI controller. As consequence, the AFLPI controller has an excellent dynamic performance of speed and torque control is evident despite the stator resistance variation, even on the alternating speed test as shown in Figure 5 (c) and Figure 5 (d). 


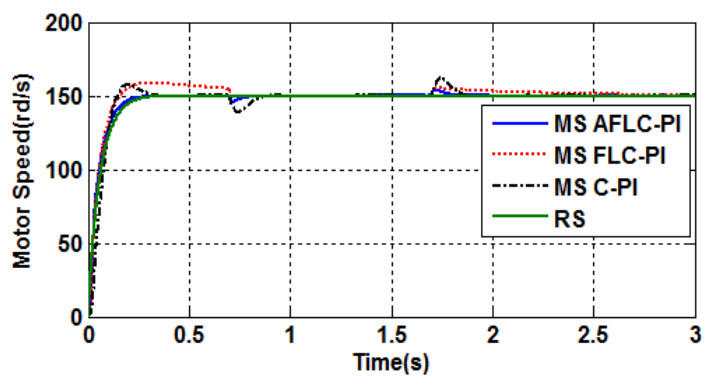

(a)

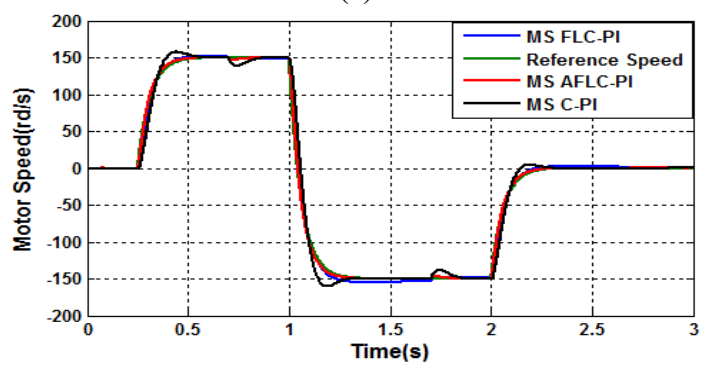

(c)

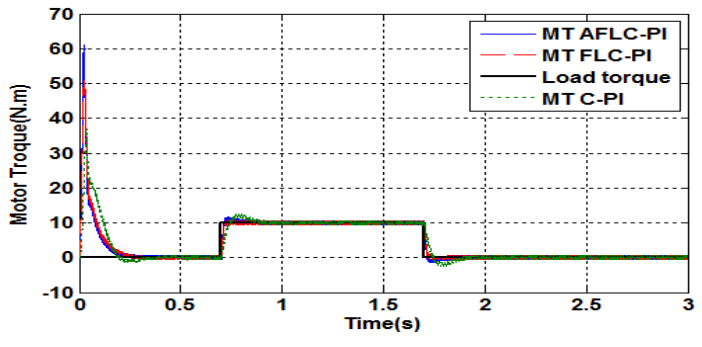

(b)

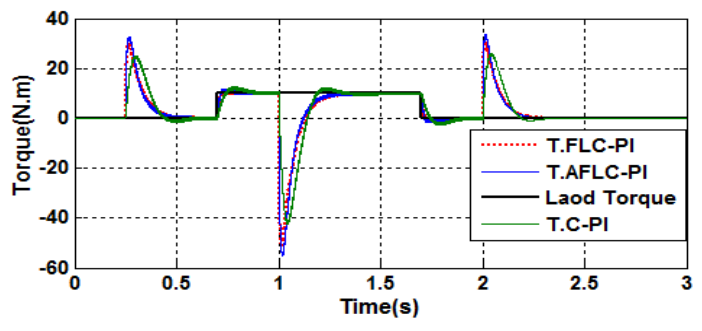

(d)

Figure 4. Rotation speed and electromagnetic torque evolution in perturbed case during $\mathrm{Rr}=1.5 \mathrm{Rr}$. (a) Rotation speed for a steady-state reference speed conditions. (b) Electromagnetic torque corresponding to the rotor speed conditions. (c) Rotation speed for an alternate reference speed conditions. (d) Electromagnetic torque corresponding to the rotor speed conditions.

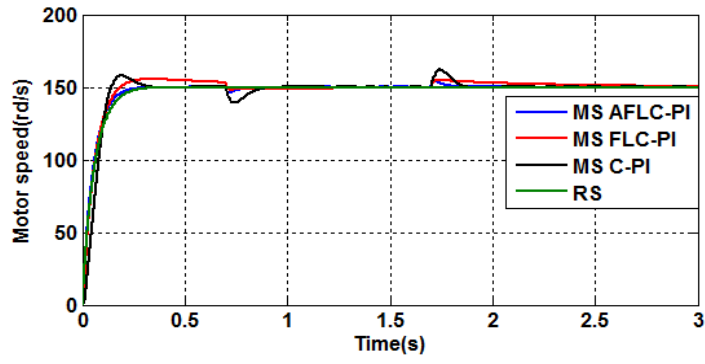

(a)

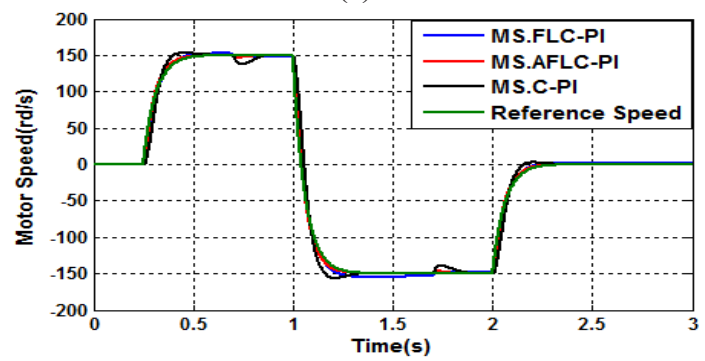

(d)

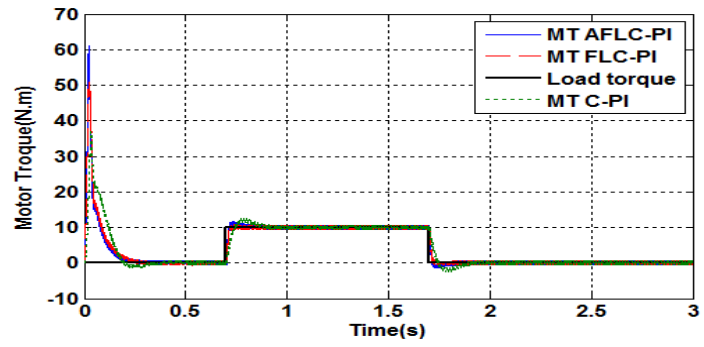

(b)

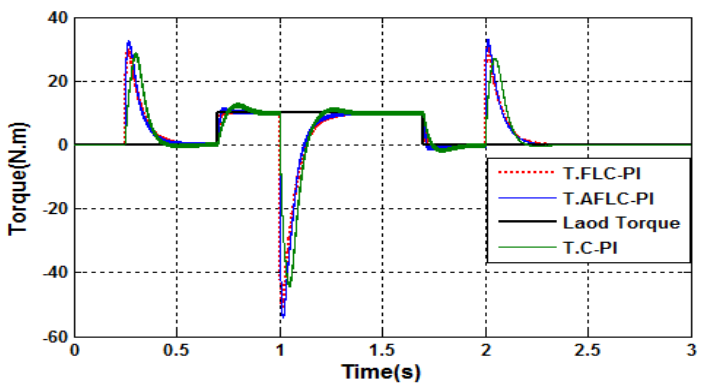

(d)

Figure 5. Rotation speed and electromagnetic torque evolution in perturbed case during Rs $=1.5 \mathrm{Rs}$.

a) Rotation speed for a steady-state reference speed conditions.

b) Electromagnetic torque corresponding to the rotor speed conditions.

c) Rotation speed for an alternate reference speed conditions.

d) Electromagnetic torque corresponding to the rotor speed conditions. 
Test 3: an increasing of the inertia $\mathrm{J}=1.5 \mathrm{~J}$. The speed and electromagnetic torque tracking are respectively shown in Figure 6 (a) and Figure 6 (b). The proposed AFLPI controller shows a significant improvement in the time interval corresponding to the period of rapidly changing load conditions in term of response time and overshoot. The inertia variation has a little influence on the AFLPI controller and shows an excellent dynamic performance in case of alternating speed (Figure 6 (c) and Figure 6 (d)) compared with the FLPI or conventional PI controllers.
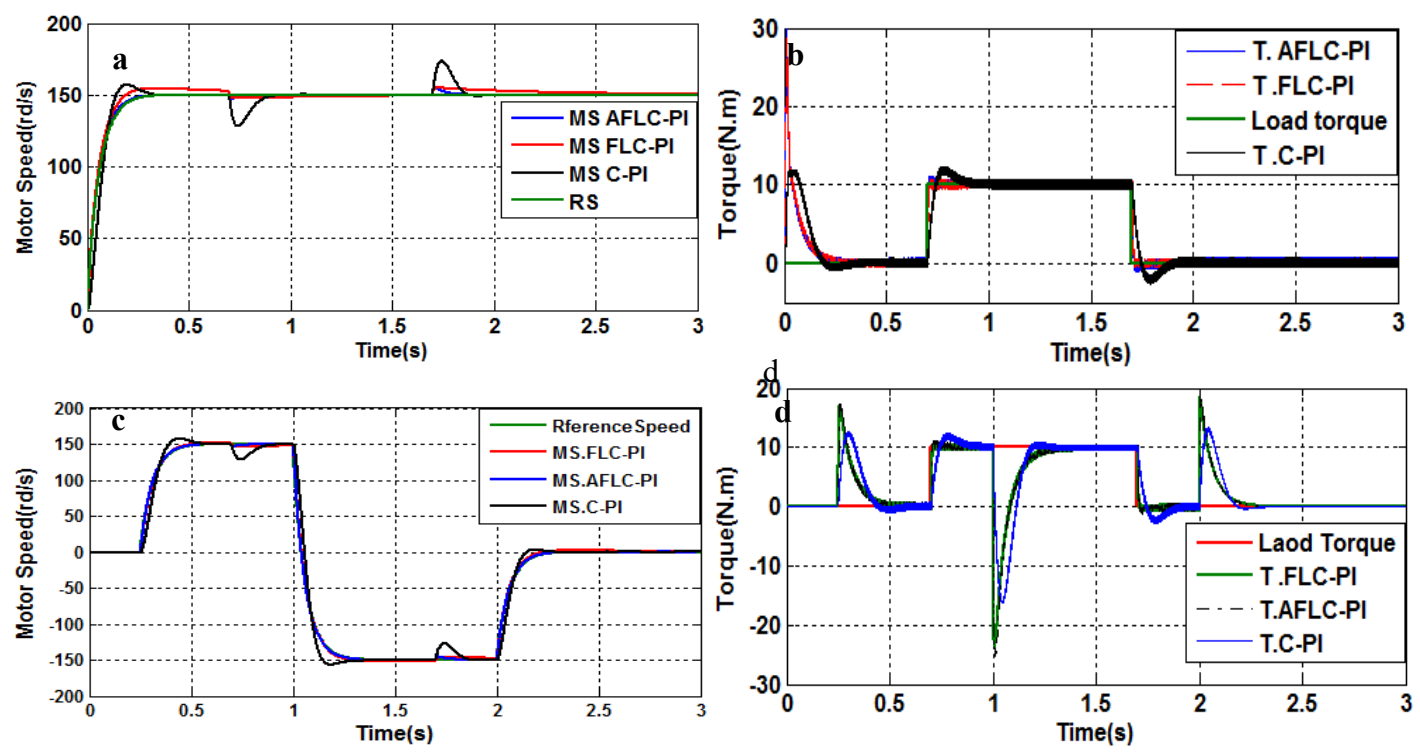

Figure 6. Rotation speed and electromagnetic torque evolution in perturbed case during $\mathrm{J}=1.5 \mathrm{~J}$.

(a) Rotation speed for a steady-state reference speed conditions. (b) Electromagnetic torque corresponding to the rotor speed conditions. (c) Rotation speed for an alternate reference speed conditions. (d) Electromagnetic torque corresponding to the rotor speed conditions.

\section{CONCLUSION}

The main purpose of this work is to take care of the torque as well as the speed of a DFIM using an appropriate vector control diagram. The stability of the control system is ensured by a way of conceiving this same control. The developed model is presented unlike the controllers proposed for DFIM because not requiring any mathematical model of the DFIM type following a simulation and the reader of the results there of, it has been proved that the adaptive fuzzy controller is far more effective in terms of ability to achieve more focused tracking and better monitoring of torque and speed and at the same time a more appropriate level of flow control in the presence of unstructured model and load uncertainties not known in all cases, and especially this fuzzy adaptive control system which we are talking about has proven to be more efficient in carrying out the follow-up command than the linearization vector system operating by feedback ultimately and in perspective of future research and work will target the putting into practice (in experimentation) of this controller subject of this work.

\section{REFERENCES}

[1] Dettori S, Iannino V, Colla V, Signorini A. "A Fuzzy Logic-based Tuning Approach of PID Control for Steam Turbines for Solar Applications," Energy Procedia; Vol. 105, pp. 480-5, 2017.

[2] Zemmit A, Messalti S, Harrag A. "A new improved DTC of doubly fed induction machine using GA-based PI controller," Ain Shams Eng J, Vol. 9, pp. 1877-85, 2018. doi:10.1016/j.asej.2016.10.011.

[3] Payam AF. "An Adaptive Input-Output Feedback Linearization Controller for Doubly-Fed Induction Machine Drives," J Electr Eng, Vol5, pp. 139-54, 2008.

[4] Belfort C. "Field Oriented Control of a Double Fed Asynchronous Machine: Modelling and Implementation," IFAC Proc Vol 1997;30:1101-6. doi:10.1016/S1474-6670(17)43510-5.

[5] Tir Z, Malik OP, "Eltamaly AM. Fuzzy logic based speed control of indirect field oriented controlled Double Star Induction Motors connected in parallel to a single six-phase inverter supply," Electr Power Syst Res; Vol. 134, pp. 126-33, 2016. doi:10.1016/j.epsr.2016.01.013. 
[6] Cherifi D, Miloud Y. "Performance analysis of adaptive fuzzy sliding mode for nonlinear control of the doubly fed induction motor," Indones J Electr Eng Informatics,Vol. 6, pp. 436-47, 2018. doi:10.11591/ijeei.v6i1.605.

[7] Aroussi HA, Ziani E, Bossoufi B. "Contribution to the enhancement of dual dtc application: Doubly fed induction motor," Proc- 3rd Int Conf Adv Technol Signal Image Process ATSIP 2017, 2017. doi:10.1109/ATSIP.2017.8075608.

[8] Babouri R, Aouzellag D, Ghedamsi K. "Introduction of doubly fed induction machine in an electric vehicle," Energy Procedia, Vol 36, pp. 1076-84, 2013. doi:10.1016/j.egypro.2013.07.123.

[9] Wang Y, Chen H, Wang W, Xiao T. "Adaptive control for a class of nonlinear systems via T-S fuzzy logic systems with nonlinear rule consequents.' Proc 2015 27th Chinese Control Decis Conf CCDC 2015, pp. 376-81, 2015. doi:10.1109/CCDC.2015.7161721.

[10] Chaoui H, Sicard P. "Adaptive fuzzy logic control of permanent magnet synchronous machines with nonlinear friction," IEEE Trans Ind Electron, Vol. 59, pp. 1123-33, 2012. doi:10.1109/TIE.2011.2148678.

[11] Tripathi SM, Mishra A, Pandey AK. "High performance speed tracking of CSI-fed SCIM drive employing a variable-gain proportional-integral (VGPI) speed controller,” J Electr Syst Inf Technol, Vol. 5, pp, 635-52, 2018. doi:10.1016/j.jesit.2017.08.001.

[12] Bounar N, Boulkroune A, Boudjema F, M'Saad M, Farza M. "Adaptive fuzzy vector control for a doubly-fed induction motor," Neurocomputing, Vol. 151, pp. 756-69, 2015. doi:10.1016/j.neucom.2014.10.026.

[13] Ramadan EA, El-Bardini M, Fkirin MA. "Design and FPGA-implementation of an improved adaptive fuzzy logic controller for DC motor speed control," Ain Shams Eng J, Vol 5, pp. 803-16, 2014. doi:10.1016/j.asej.2014.04.002.

[14] Zaki AM, El-Bardini M, Soliman FAS, Sharaf MM. "Embedded two level direct adaptive fuzzy controller for DC motor speed control," Ain Shams Eng J, Vol. 9, pp. 65-75, 2018. doi:10.1016/j.asej.2015.10.003.

[15] Lin TC, Liu HL, Kuo MJ. "Direct adaptive interval type-2 fuzzy control of multivariable nonlinear systems," Eng Appl Artif Intell, Vol. 22, pp. 420-30, 2009. doi:10.1016/j.engappai.2008.10.024.

[16] Li Y, Tong S. "Command-filtered-based fuzzy adaptive control design for MIMO-switched nonstrict-feedback nonlinear systems," IEEE Trans Fuzzy Syst, Vol. 25, pp. 668-81, 2017. doi:10.1109/TFUZZ.2016.2574913.

[17] Sathishkumar H, Parthasarathy SS. "A novel fuzzy logic controller for vector controlled induction motor drive," Energy Procedia, Vol. 138:686-91, 2017. doi:10.1016/j.egypro.2017.10.201.

[18] Keltoum L, Leila B, Abderrahmen B. "Speed control of a Doubly-Fed induction motor (DFIM) based on fuzzy sliding mode controller," Int J Intell Eng Syst, vol 10, pp. 20-9, 2017. doi:10.22266/ijies2017.0630.03.

[19] Loukal K, Benalia L. "Interval type-2 fuzzy gain-adaptive controller of a Doubly Fed Induction Machine (DFIM)," J Fundam Appl Sci, Vol. 8, pp. 470, 2016. doi:10.4314/jfas.v8i2.20.

[20] Georges S, Rita M, Maria P, "Analysis AH Mixed Sensitivity H' Control of Doubly Fed Induction Motor," 2007:1300-4.

[21] Hasni M, Mancer Z, Mekhtoub S, Bacha S. "Parametric identification of the doubly fed induction Machine," Energy Procedia, Vol. 18, pp. 177-86, 2012. doi:10.1016/j.egypro.2012.05.029.

[22] El Ouanjli N, Motahhir S, Derouich A, El Ghzizal A, Chebabhi A, Taoussi M. "Improved DTC strategy of doubly fed induction motor using fuzzy logic controller," Energy Reports, vol. 5, pp. 271-9, 2019. doi:10.1016/j.egyr.2019.02.001.

[23] Ben Attous D, Bekakra Y. "Speed control of a doubly fed induction motor using fuzzy logic techniques," Int $J$ Electr Eng Informatics, Vol. 2, pp. 179-91, 2010.

[24] Kar BN, Mohanty KB, Member S, Singh M. "Indirect Vector Control of Induction Motor Using Fuzzy Logic Controller" 2011:6-9.

[25] Taoussi M, Karim M, Bossoufi B, Hammoumi D, Lagrioui A, Derouich A. "Speed variable adaptive backstepping control of the doubly-fed induction machine drive," Int J Autom Control, Vol. 10, pp. 12, 2016. doi:10.1504/IJAAC.2016.075140.

Int J Pow Elec \& Dri Syst Vol. 11, No. 1, Mar 2020 : $496-504$ 